\title{
Historical Perspectives of Surgical Infections
}

\author{
Wilson I. B. Onuigbo \\ Department of Pathology, Medical Foundation and Clinic, 8 Nsukka Lane, Enugu, Nigeria \\ *Corresponding Author: Wilson I. B. Onuigbo, Department of Pathology, Medical Foundation and \\ Clinic, 8 Nsukka Lane, Enugu, Nigeria
}

\begin{abstract}
Background: The surgeon has for centuries borne the brunt of the ill effects of infection. This review concerns its history.
\end{abstract}

Methods: In consonance with the advice of Burnet, some knowledge should be acquired concerning historical data before starting new research.

Results: Numerous examples were documented from the early centuries to the present days.

Conclusion: There is the dictum that "the surgeon's basic requirement is a healed wound." Surgeons must not only still pursue the known causes of sepsis but also eliminate those of the future!

Key words: History, infection, surgery, drainage, cure.

\section{INTRODUCTION}

An American Professor reviewed the historical perspectives of surgical drainage in the British Journal of Surgery in 1986. "History," he wrote [1], "furnishes us with a picture that demonstrates the problems which our forebears faced and which face us today." This agrees with Burnet [2] who stated that pertinent historical information should be acquired before starting to do research. Therefore, I propose to supply selected materials with my library containing historical photocopies. Surely, perspectives of how the old masters themselves faced surgical infections ought to be documented even if at second hand.

\section{Historical TEXTS}

Operator of note was the celebrated EI Zahrawi (936-1013 AD). In a paper read during the 15th Conference of the Sudan Association of Surgeons held in Khartoum in 1979, Ismail Nabri [3], FRCS, dwelt on him. I like best how that grand master was portrayed in terms of surgery and as regards "working with one's own hands." As that father fathomed:

My sons, I would like you to know that there are two kinds of "working with our hands": that which is accompanied by safety and that which ends in disaster. I have therefore drawn your attention in every section of this book to the kind of work that is disastrous so that you will avoid embarking on it and thereby avoid giving chances to the ignorant and the wicked who are always ready to defame you. So please seek dignity and conscientiousness for yourselves and assurance and safety for your patients.

Consider 1513 when the then current thinking was as follows [4]:

Obviously these early surgeons realized the importance of the dura mater as a protective barrier against infection and the danger, when it was broken, of empyemas or meningitis.

Mark Ravitch [5] of the University of Pittsburgh looked at Surgery as it was practiced around the year 1776. Let us consider but one of the examples:

Surgeons have always inclin'd to conceive (that) there is something more mysterious in these wounds than any others; but their terribleness is owing to the violent contusion and laceration of the parts, and often to the admission of extraneous bodies into them, as the bullet, splinters, clothes, etc. and were any other force to do the same thing, the effect would be exactly the same as when done by Fire-Arms. The treatment of these wounds consists in removing the 
extraneous body as soon as possible, to which end the patient must be put into the same posture as when he received the wound: if it cannot be extracted by cutting upon it, which should always be practised when the situation of the bloodvessels, etc., does not forbid, it must be left to nature to work out.

Meningitis was greatly feared. Thus, the very nicely named Richard Wiseman [6] was reported to have taught as follows:

The blood covering the dura should be removed and then washed out. "If there be sanies /old liquefying hematoma/or putrefaction/empyema /... higher detergents should be used to wash it out."

Out of despair, Theodor Billroth [7], who did twenty thyroid ectomies in Zurich in $6 \frac{1}{2}$ years with one death from haemorrhage and seven from sepsis abandoned thyroid surgery for a 10year period. Happily, this 40 percent mortality was to improve to 8.3 percent when he used Lister's antiseptive operative technique and Spencer Well's haemostats and performed 48 thyroid ectomies between 1877 and 1881 in Vienna where he was described as a "rapid operator."

Out of the galaxy of surgical giants, let me select Alexander Ogston [8] from good old Scotland where I was a student long ago. It was said of him at great length as follows:

Then, when his mind had been sensitized by these thoughts, James Davison presented himself in the out patients with an acute abscess. Ogston let the pus, took it home, stained it with methyl violet and examined it under a student's microscope with a $1 / 4$ " objective. "My delight may be conceived when there were revealed to me beautiful tangles, tufts and chains of round organisms in great numbers, which stood out clear and distinct among the pus cells and debris.' 'The pus on the microscope slide, which appeared to indicate the solution of a great puzzle, filled me with hope.' ...

He then set out to test his theory that micrococci cause surgical sepsis by applying the criteria recently described by Robert Koch (who was incidentally a general practitioner at the time). Ogston built a laboratory in his garden with the intention of doing animal experiments.
The primitive methods for culturing bacteria at that time proved unsatisfactory, but he hit on the idea of inoculating eggs under Listerian precautions, of incubating them, and of passing the cultures from egg to egg. The pure cultures obtained were injected into guigea pigs and mice, with results that he felt were absolutely conclusive....

Nothing daunted, Ogston went to Berlin for the German Surgical Association Meeting, and on 9th April 1880 he gave a paper 'On Abscesses,' which was well received. His very modern sounding conclusions were as follows: (1) Micrococci are the commonest cause of the acute abscesses. (2) Pus formation is associated with the presence of micrococci. (3) Micrococci can cause blood poisoning. (4) There is a strong individual factor in the outcome of infection.

In the Bulletin of the New York Academy of Medicine was printed a wide-ranging Symposium in Memory of Lister [9]. It was said of him that, whilst in the wards, he saw with his own eyes those dire diseases which practically always followed compound fractures or operations-septicaemia, pyaemia, erysipelas, "hospital gangrene," and tetanus. This was exemplified as follows:

By 1867 Lister was able to report eleven cases of compound fracture successfully treated by his new method. Lister's principles, which he held to through thick and thin, proved to be correct and were justified before the bar of reason and shown to be true by experiment and surgical practice. In 1867 for the first time he was able to state that in his wards, "during the past nine months not a single instance of pyaemia, hospital gangrene, or erysipelas has occurred," and could safely increase the accommodation of the wards by placing mattresses between the beds. It is difficult for us now to contrast this state of affairs with the horrors of sepsis in hospital surgical practice, which were seen before that date....

\section{DISCUSSION}

Dates with history may be kept by drawing attention to the pioneers in obstetrics [10], hand surgery [11], ophthalmology [12], vascular 
surgery [13], orthopaedics [14], neurosurgery [15], dermatologic surgery [16], plastic surgery [17], urology [18], colorectal surgery [19] and prevention of bone and joint infections [20]. To return to urology [21], I cannot resist reproducing one more historical account:

The doubts and anxieties of a surgeon, immediately before a Royal operation, are mirrored in the letter (that) Thompson wrote to his wife: "I slept only one and a half hours last night ... I got thinking about my case and I got horribly anxious about it in the night.... In spite of his anxieties, Thompson operated with complete success and the King made a remarkably rapid and successful recovery. It was only some years later that Thompson worked out why his Royal patient had such a smooth postoperative course, whereas the manipulations of his previous surgeons had always been followed by a sharp unpleasant fever. By now the antiseptic theory was well established and Thompson remembered that he himself had employed new instruments, freshly unpacked from their oily, greasy and sterile wrappings, on the King. This was in contrast to the instruments of Civiale and Langenbeck that had been thoroughly inoculated with the bacteria of hundreds of previous patients.

\section{CONCLUSION}

What of current trends? They include modernization of medical microbiology services [22], recognition of its role in surgical progress [23], attention to perioperative hygiene and prophylactic antibiotic treatment [24], rapid identification of nosocomial germs [25], and the dictum that "the surgeon's basic requirement is a healed wound" [26]. In this context, we must do all we can not only to still pursue the causes of sepsis but also to strive to eliminate them even nowadays!

\section{REFERENCES}

[1] Robinson JO. (1986) Surgical drainage: an historical perspective. Br J Surg, 73:422-426.

[2] Burnet M. Morphogenesis in cancer. Med J Aust, 1977; 1:5-9.

[3] Nabril IA. EI Zahrawi (936-1013 AD), (1983) the father of operative surgery. Ann Roy Coll Surg Eng, 65:132-134.

[4] Bakay L. (1986) Surgical treatment of brain laceration in 1513. Surg Neurol, 25:568-570.
[5] Ravitch MM. (1977) Surgery in 1776. Ann Surg, 186:291-300.

[6] Bakay L. (1987) Richard Wiseman, a royalist surgeon of the English Civil War. Surg Neurol, 27:415-418.

[7] Harwick RD. (1988) Our legacy of thyroid surgery. Am J Surg, 156:230-234.

[8] Lyell A. Alexander Ogston (1844-1929) (1977) - Staphylococci. Scott Med J, 22:277-278.

[9] Malloch A. (1928) Biographical sketch and memorabilia of Lister. Bull New York Aca Med, 4:133-147.

[10] Hiddinga A. (1987) Obstetrical research in the Netherlands in the nineteenth century. Med Hist, 31:281-305.

[11] Pfeffer GB, Gelberman RH, Boyes JH, et al. (1988) The history of the carpal tunnel syndrome. J Hand Surg Br. 13:28-34.

[12] Winstanley J. (1978) Ophthalmology at St Thomas' Hospital, London: The 12th to the 19th centuries. Surv Ophthamol, 22:341-347.

[13] Dale WA. (1974) The beginnings of vascular surgery. Surgery, 76:849-866.

[14] Beasly AW. (1982) The origins of orthopaedics. J Roy Soc Med, 75:648-655.

[15] Ljunggren B, Säveland H, Brandt Let al. (1984) Aneurysmal subarachnoid hemorrhage Historical background from a Scandinavian horizon. Surg Neurol, 22:605-616.

[16] Marmelzat WL. (1987) History of dermatologic surgery from the beginnings to late antiquity. Clin Dermatol, 5:1-10.

[17] Bennett JP. (1983) Aspects of the history of plastic surgery since the 16th century. J Roy Soc Med, 76:152-157.

[18] Dimopoulos C, Gialas A, Likourinas M, et al. (1980) Hippocrates: Founder and pioneer of urology. Br J Urol, 52:73-74.

[19] Graney MJ, Graney CM. (1980) Colorectal surgery from antiquity to the modern era. Dis Col Rect, 23:432-441.

[20] Norden CN. Prevention of bone and joint infection. Am J Med, 1985; 78: 229-232.

[21] Ellis H. (1979) A history of bladder stone. J Roy Soc Med, 72:248-251.

[22] Duerden B. (2007) Infection protection: modernizing medical microbiology services. Bull Roy Coll Pathol, 139:19-21.

[23] Alexander JW. (1985) The contributions of infection control to a century of surgical progress. Ann Surg, 201:423-428.

[24] Hambraeus A. (1987) A microbiologist's view on perioperative hygiene and prophylactic antibiotic treatment. Acta Chir Scand, 538:96100.

[25] Ghaith DM, Hassan RM, Hasanin AM. (2015) Rapid identification of nosocomial 
Acinetobacter baumannii isolated from a surgical intensive care unit in Egypt. Ann Saudi Med, 36:440-444.
[26] Bucknall TE. (1985). Factors affecting the development of surgical wound infections: a surgeon's view. J Hosp Infect, 5:1-8.

Citation: Wilson I. Historical Perspectives of Surgical Infections. International Journal of Research Studies in Medical and Health Sciences. 2017;2(5):1-4.

Copyright: ( ) 2017 Wilson I.. This is an open-access article distributed under the terms of the Creative Commons Attribution License, which permits unrestricted use, distribution, and reproduction in any medium, provided the original author and source are credited. 